\title{
Towards the Spatial Analysis of Vague and Imaginary Places: Evolving the Spatial Humanities through Medieval Romance
}

Patricia Murrieta-Flores, Digital Humanities Research Centre, University of Chester.

\section{p.murrietaflores@chester.ac.uk}

Naomi Howell, English Department, University of Exeter.

\section{N.E.Howell@exeter.ac.uk}

Keywords: Spatial Humanities; Literary GIS; Imaginary geographies; Fuzzy place; Medieval Literature; French Romance; Digital Humanities; Corpus Linguistics; historical corpora; spatial narratives.

\section{Abstract}

The establishment of the field of Spatial Humanities testifies to the success in the use of technologies such as Geographic Information Systems (GIS) for the analysis of texts in Humanities. Although the increasing volume of projects can be regarded as a sign of advance, an important challenge has remained unsolved in this field and it has been barely addressed. The majority of research dealing with spatial narratives in historical and literary corpora, focus on the investigation of what can be called 'real' geographies. This is to say, places that can be located and analysed through coordinates in software such as GIS. The challenge, however, is that a large number of narratives deal with places that are geographically vague and/or imaginary. We presented this challenge at the Digital Humanities Conference during the summer of 2016 as part of the workshop 'A Place for Places' from which this volume emerges. On it, we posed the question: How can we, through computational methods, move into the analysis of spatial narratives incorporating real, vague, and imaginary space and place? Looking to address this key question and using the iconic French medieval romances of Chretién de Troyes as example, this article presents a preliminary analysis that implements a tailored methodology combining a spatial and linguistic approach for the 
analysis of real, vague and imaginary space and place in historical literature. 


\section{Introduction and challenge}

The success so far of Spatial Humanities as a field can be summarised in the increasing amount of research and publications engaging with the exploration of geographies in literary and historical texts. Research and projects such as "Mapping the Lakes" (Cooper and Gregory 2011; Gregory and Cooper 2009), the "Cultural Atlas of Australia" (Stadler et al. 2016), "A Literary Atlas of Europe" (Piatti 2016), "Mapping the Emotions of London" (Heuser et al. 2016), and "Spatial Humanities: GIS, Texts \& Places" (Murrieta-Flores et al. 2015; Gregory et al. 2015; Cooper et al. 2016) among many others, have successfully integrated the use of Geographic Information Science approaches and technologies with Humanities research. However, although the sheer volume of these inquiries signals the growth in the development of Spatial Humanities in general, it is also true that this growth has not been consistent or without challenges. While the creation of digital literary atlases and the use of 'distant reading' has demonstrated the utility of Geographic Information Systems (GIS) and other mapping techniques, facilitating scholarship by means of contextualizing places depicted in large collections or corpora, it has also ignited important debates about the utility and merits of macro-mapping approaches. Since then, the use of more advanced spatial analysis has also contributed to the expansion of the field, demonstrating that spatial approaches can bring unparalleled benefits and new ways of thinking about 'place' in literature and history. Humanitiesbased approaches such as Geographical Text Analysis (Murrieta-Flores et al. 2015; Porter et al. 2015; Donaldson and Gregory 2016) have enabled the semi-automatic geographic exploration of large collections of texts or corpora in literary and historical contexts, but in the particular case of digital literary projects, the study of the spatial dimension has been focused on what could be broadly thought of as two main goals, as Saunders (2016) has pointed out. The first could be seen as the exploration of the role of maps and space within the narrative of literary works; the second could be thought of as the investigation of how new reader-generated maps, spatial analyses and Geographic Information Systems (GIS) might give us new insights to the spatial world within individual or multiple works of literature (Gregory and Cooper 2009; Cooper and Gregory 2011; Cooper and 
Priestnall 2011; Reuschel and Hurni 2011; Alves and Queiroz 2013; Donaldson et al. 2015). This has been mainly accomplished through the digital exploration of corpora with GIS and other spatial tools, and it has only been possible due to the nature of the texts used and the mention of placenames in them. This is to say that: (1) the texts have to have a geographical nature, and that (2) in order to be 'mappable', it has to be possible to allocate coordinates to the places mentioned. In the Humanities, the very first exercises were done manually, simply collating the place-names mentioned in the text into a list, in order to eventually map them (Gregory and Cooper 2009). In more recent developments, the integration of Corpus Linguistic analyses, Natural Language Processing (NLP) techniques and GIS methodologies have allowed the semi-automatization of this process and there are several examples from different disciplines approaching the identification and extraction of place references in textual documents and their visualisation (Adams et al, 2015; Borin et al, 2014; Gregory and Hardie, 2011).

Although the techniques developed within the field of Spatial Humanities are proving of great success in the exploration of geographies in corpora, and despite their tangible benefits, a great challenge remains. The above focus substantially on what can be called 'real' geographies. This is to say, places, usually identified by place-names that can be accurately located by their coordinates in a map. Other approaches within the fields of Computational Sociolinguistics and Geographic Information Retrieval (GIR) have looked to address the difficult challenges of place reference resolution, which might include the use of vernacular names and geography (e.g. Gringolandia, The Alps) and vague features or ambiguous geographical data (e.g. downtown, south of Britain) (Fisher 2000; Pasley et al., 2007; Montello et al., 2014; Melo and Martins, 2016;). The problem here is that a great many literary narratives, in addition to real geographies, vernacular names, and ambiguous geographical information, might also deal with places that are simply fantastic or imaginary. On the one hand, although it has to be acknowledged that geographers and fields such as GIR, have previously encountered and discussed at length issues related to place reference resolution including the identification, retrieval and analysis of ambiguous or vague geographies in corpora, 
and there has been a fair amount of research aiming to address the modelling, particularly of vague geographies through a variety of techniques (Pasley 2007; Jones et al, 2008; Twaroch et al., 2008; Kanagavalli and Raja, 2013; Montello et al., 2014; Purves and Derungs, 2015; Melo and Martins 2016), this has been done using mainly modern data, rarely in the literary context, and addressing particularly imaginary place and space. On the other hand, although in the context of Digital Humanities the importance of these uncertain, vague or non-geographical spaces has been extensively discussed (Piatti et al. 2009; Reuschel and Hurni 2011; Bär and Hurni 2011; Reuschel, Piatti and Hurni 2013; Piatti, Reuschel, Hurni 2013; Travis 2015; Bushell 2016; Stadler et al., 2016; Piatti 2016; ), only few attempts have been made in this field in terms of developing methodological or digital approaches to help scholars identify, analyse and study these places in the context of literary and historical works. It can be said then, that although there has been some advance in addressing spatial uncertainty of real geographies in modern contexts, little has been done to fully study and address the interplay between real, vague and imaginary places in historical literature. In addition, it has to be not only considered that fictional spaces are fragmentary as they are constructed by words that are to be completed and developed by the imagination of the reader (Reuschel and Hurni 2011: 294), but also that conceptions of geography and place change with time and culture (Lefebvre 1991; Mark and Frank 1996; Rouse 2014:16), and therefore, careful consideration has to be paid to the context of the literature analysed.

This becomes of great relevance if we are aiming to develop methodologies and techniques that allow us to understand the complexity of place and space in literary and historical corpora. At this stage, as demonstrated by the multiple successful projects in the field of Spatial Humanities, it is clear that we can perform and map spatial analysis of real geographies mentioned in corpora. However, the ultimate question in order to advance the Spatial Humanities as a field becomes:

- How can we move forward through computational techniques into the analysis of space and place in textual sources, integrating their full complexity holistically? 
Using a group of medieval romances as a case study and building on Lefebvre's original proposition that our understanding of space and place changes with time and culture, the objective of our research is to delve into this question. In doing so, we propose a preliminary exploratory methodology that, combining spatial technologies and a linguistic approach, aims to facilitate the analysis of medieval narratives, accounting for the spatial complexity portrayed, as well as integrating and expediting the exploration of geographical, vague and imaginary space and place in Humanities-based fields.

\section{Space and place in medieval romance}

In the twelfth century, narratives of magic, chivalry, exploration and love came to be performed and written not in Latin but in the vernacular or, as it was called in Old French, romanz. It was this term-originally referring to the linguistic medium rather than subject matter-which gave the genre romance its name. These episodic, often very lengthy tales, which followed their itinerant protagonists through a series of adventures, soon acquired a range of recognisable formal characteristics which could showcase the skill and erudition of their composers and elicit complex responses from their audiences. Sometimes considered to be 'the most prominent, sophisticated, and widely disseminated species of literary narrative' (Heng 2003, 2) of the Middle Ages, the genre has deep roots in folklore, history, spirituality and religious ritual, travel writing, and classical antiquity. In short, romance called a wide array of cultural and historical contexts into play. The resulting scope of these remarkably capacious narratives could thus incorporate both the intimately familiar and the extraordinary, the marvellous, the monstrous, the past, and the geographically distant. The world of romance can thus dilate from the inner workings of the human heart to the limits of the known world.

In the last two decades, literary studies have been increasingly concerned with the roles that place and space play in narratives, thereby informing cultural depictions, social interactions and even influencing political discourses (Harvey 1990; Lefebvre 1991; Howes 2007; Tally 2011). Despite or 
because of their fabulous, inventive content, medieval romances have proven to be remarkably apt mirrors of such cultural knowledge. More than this: they played an active and vital part in fashioning and transmitting values, morals and ideals: what today we might call ideology. As a key form of common access to knowledge, romances served as the reader's or auditor's 'eyes' to the world: they could act as a kind of travel literature, guiding the reader through places that he or she would probably never visit. Yet they could also enhance the experience of place for both denizen and traveller by being performed in some of the very locations they narrated. Beyond this, it has been argued that they assisted the construction and promulgation of class and gender roles, as well as in the production of national (linguistic, cultural, political) identities and their legendary origins. These 'eyes', then, might be said to see the world through lenses of ideological discourse (Rouse 2014).

Romance narratives and the places they moved through and evoked, could perform ideological functions in a manner analogous to contemporary world maps like the thirteenth-century Hereford and Ebstorf mappae mundi (Rouse 2011, 136). Like romance, mappae mundi incorporated knowledge from biblical, classical, and folkloric-as well as romance-sources in a necessarily selective and ideologically inflected way. The relationship with romance is so striking that in the nineteenth century it was observed that 'a medieval mappa mundi, to be duly appreciated, must to a great extent be regarded as an illustrated romance' (Bevan et al. 1873, xxii). This is not to say that the obvious distinctions between map and romance may be overlooked. A narrative like romance, which unfolds sequentially, might well be supposed to 'predispose... the reader to think historically, making it difficult to see the text as a map, a geography of simultaneous relations and meanings that are tied together by spatial rather than temporal logic' (Soja 2011, 1). Yet as scholars have observed, romance also resists sequential linearity-and is capable of producing simultaneous relations and meanings-in a number of ways (Zink 2008, 100; Baswell 2006, 21-29; Blumenfeld-Kosinski 2002, 193-95; Nichols 1992, 149). Like the Hereford map, romances interacted with their readers / viewers / audiences in a way which sought to engage multiple senses and associations. Put another way, romance could not only awaken and manage the recollection of recognisable places, past events, 
and narratives, but they could generate new experiences, new memories for the future, and perhaps, new geographies. Geraldine Heng has asked, 'Can geography and place be a subject of romance, along with human actors engaged in love, quest, and marvellous adventure?' (Heng 2003, 1). We would answer yes, but more than this, geography and place are modes whereby romance unfolds its narratives of love, quest, and adventure.

Romances engaged with inter- and extra-textual cultural resources which made them particularly well suited for ensuring the preservation of the authority and perpetuation of the chivalric ideals of their elite audiences (McKinstry 2012). This strategy was so effective that kings and princes from Edward I (1239-1307) onward sought to identify themselves as knights-even, under Edward III, constructing a 'Round Table' at Winchester (Biddle et al. 2000, 360-61; Prestwich 1988, 120-21)-in order to strengthen and add lustre to their authority and their aspirations of territorial expansion. Renewed fascination with medieval chivalry in the Victorian Period was similarly linked with glamour, power, and colonial expansion (Cannadine 2002, 122-28). A long tradition of discourse in later eras has imagined the entire Middle Ages 'as a romance' (Heng 2003, 2; Ganim 1996, 149).

Even so, romance could never have ignited elite and popular, male and female interest if it were unambiguously didactic and moralizing. Part of the fascination which romance held and still holds for audiences resides in its uncanny capacity to invoke radically alternative values, which can threaten and subvert authority (Crane 2002; Guynn 2000; Baswell 2000; Cohen 1997; Dinshaw 1994). The containment of these radically subversive forces enacts and is required by the assertion of power structures we described above. Yet the balance is a precarious one. Is the containment really definitive? Isn't the formulation of subversive narrative elements more risky than otherwise? The innumerable versions, translations, continuations and adaptations which romance seems to provoke on the one hand, and the contemporary condemnations of romance on the other, suggest both the inconclusiveness it fostered and the anxieties it provoked. 
All this was accomplished through the genre's engagement with personal and collective memory. Instead of simply instructing by way of rote mnemonics, ${ }^{1}$ romances stimulated a dynamic interplay between past and present that not only assisted the preservation of such principles, but also made use of objects, rituals and itineraries, as well as places, to encode identity, embedding them in memories through creative story telling (McKinstry 2012). The use of place in writing has been studied for a long time and although place can be defined in many different ways, due to its ubiquitous presence in literature, it has helped to mould attitudes in relation to gender, action and even emotion (Lutwack 1984; Jeremiah 2000). Place in the context of this research, particularly for the definition of the annotation system we designed and the aims of analysing these in the romances, is understood as nodes which have a geographical position. These, however, are far from simple abstracts as they yield human meaning, experience, and a sense of place. Ideas and conceptions of places, such as 'India' or 'Babylon' are likely to have elicit a response in the European medieval audience, related to acquired knowledge through descriptions provided by travellers and other accounts, as well as social and cultural interpretations, or in few cases, first-hand experience. Space in this research, regarded as a more conceptual definition, can take a wider meaning where both, the author and the audience can actively participate in its construction. This is the case for instance of ' $a$ forest' where the audience might recall a 'familiar' forest, but to which the author might actively give shape through narrated imagery, fantastic actions and descriptions. Space in romance, however, not only serves as a setting for action, but it actively shapes it, affecting and inflecting emotions and perceptions in both the characters and the audience. As such, literature engages not only with the physical world, but also with culturally specific settings and meanings of places, feeding back into the actions that take place in them, as well as being transformed by them.

\footnotetext{
${ }^{1}$ By 'rote mnemonics' we mean the exact, systematic, routine, conscious and intentional acquisition and storage of knowledge in memory (eg, Chaucer's Sergeant of Law in the Canterbury Tales, General Prologue, 327) as opposed to the more subliminal, associative memories ignited by romance. Thus we use 'mnemonics' in the more limited, modern sense. In the Middle Ages this was a rich and complex skill or art often, as it happens, imagined spatially. See Mary Carruthers, The Book of Memory: A Study of Memory in Medieval Culture (Cambridge: 1990, 2008).
} 
Produced and consumed by particular socio-cultural group(s), medieval romances may have been the conduit for the praise, credit and authoritative portrayal of particular values attached to these groups, and place and space are built into the romance through cultural ideas, knowledge and traditional associations, as well as the emotions and actions taking place in them. To 'map' a romance, therefore, as with many other literary genres, we cannot simply use spatial technologies, as this would entirely dismiss the complexity of the construction of space by medieval societies. Instead, within the field of Spatial Humanities, we need to look for a way to integrate the full complexity of romances, understanding them as 'textual maps' that guided their audiences not only through their narratives, but also through the 'real' world and the realms of culture and ideology.

\section{Tailored annotation to spatial narratives: A possible way forward}

Taking into account the experience already gathered in the field of Spatial Humanities, our approach to address the question posed above consisted in a combination of spatial techniques with Geographic Information Systems (GIS) and basic statistical methods used in Corpus Linguistics. While Corpus Linguistics focus on the analysis of human language through computational techniques, Geographic Information Systems can be regarded as a type of database management system that facilitates not only the storage, manipulation and visualisation of geographic information, but also all sorts of spatial analysis (Maliene et al., 2011).

In this particular study, we analysed five Old French $12^{\text {th }}$ century romances (in the original language) by one of the earliest and foremost poets of romance tradition, Chrétien de Troyes. Composed between 1170 and 1190, scholars agree on the general dating and order of composition of Chrétien's romances (Busby 1987, 65). Chrétien's first romance, Erec and Enide, was composed around 1170. This was followed by Cligés, probably composed by 1176. Lancelot and Yvain were composed simultaneously in the late 1170's. Perceval (1181-1190) was Chrétien's last romance, and one which he never completed. Chrétien worked under the patronage of Marie de Champagne 
(daughter of Eleanor of Aquitaine and Louis VII of France) and later, during the composition of Perceval, under Philip I of Flanders. We based this study on the thirteenth-century manuscript redacted by the scribe Guiot which includes all of Chrétien's romances, MS BnF Français $794^{2}$ (). The digital versions used were provided by the Universities of Ottawa and Lorraine via the Dictionnaire Électronique de Chrétien de Troyes (DÉCT:) ${ }^{3}$. Using this corpus, we generated a tailored annotation model in XML aiming to facilitate the identification of particular elements that are of our specific interest. The idea behind this tailored annotation was to experiment and test, whether annotating the corpus in such manner and expediting the process through digital enquiry would enable us to address questions such as:

- What was the geographic extension of Chrétien's written world and imagination?

- What is the role of place and space in romance? How are the geographies as well as spaces mentioned shaping the stories and influencing the narratives?

With this purpose, in addition to annotating places and spaces we also identified different elements and attributes that were of interest for our historical and literary analysis, including names, as well as actions, events, people, animals, gender, class, and emotions among many others (Fig. 1). The aim of annotating the corpus in such a nuanced way, was to also analyse in the future possible relationships and test whether we can identify through this mean, patterns and/or unexpected associations (e.g. between place and emotion or place and gender, etc.).

Although much research has been done in terms of toponym identification and annotation in GIR (Leidner 2004; 2007; Grover et al 2010; Speriosu and Baldridge 2013; Domigués and Eshkol-Taravella 2015; Santos et al., 2015; Inkpen et al., 2015), in Digital Humanities and particularly Literary Studies, there is no current consensus on how to annotate and reference place-names or space in corpora. To certain extent, this is not only due to the complexity that literature poses regarding place

\footnotetext{
${ }^{2}$ http://gallica.bnf.fr/ ark:/12148/btv1b84272526 Accessed February 5, 2015

${ }^{3}$ http://www.atilf.fr/dect Accessed January 17, 2015
} 
reference resolution and the issues shared and already addressed by much of the work in GIR, but also due to the fact that the exploration of space and place in literature by means of digital technologies is relatively new and we are still in the process of learning, not only the advantages of this kind of approach, but also to define what should be annotated according to the questions we want to solve. We are aware that annotation schemes such as SpaceML, TEI or an approach such as Linked Data might prove useful, and we will aim to convert our own tailored schema to one of them in future work.

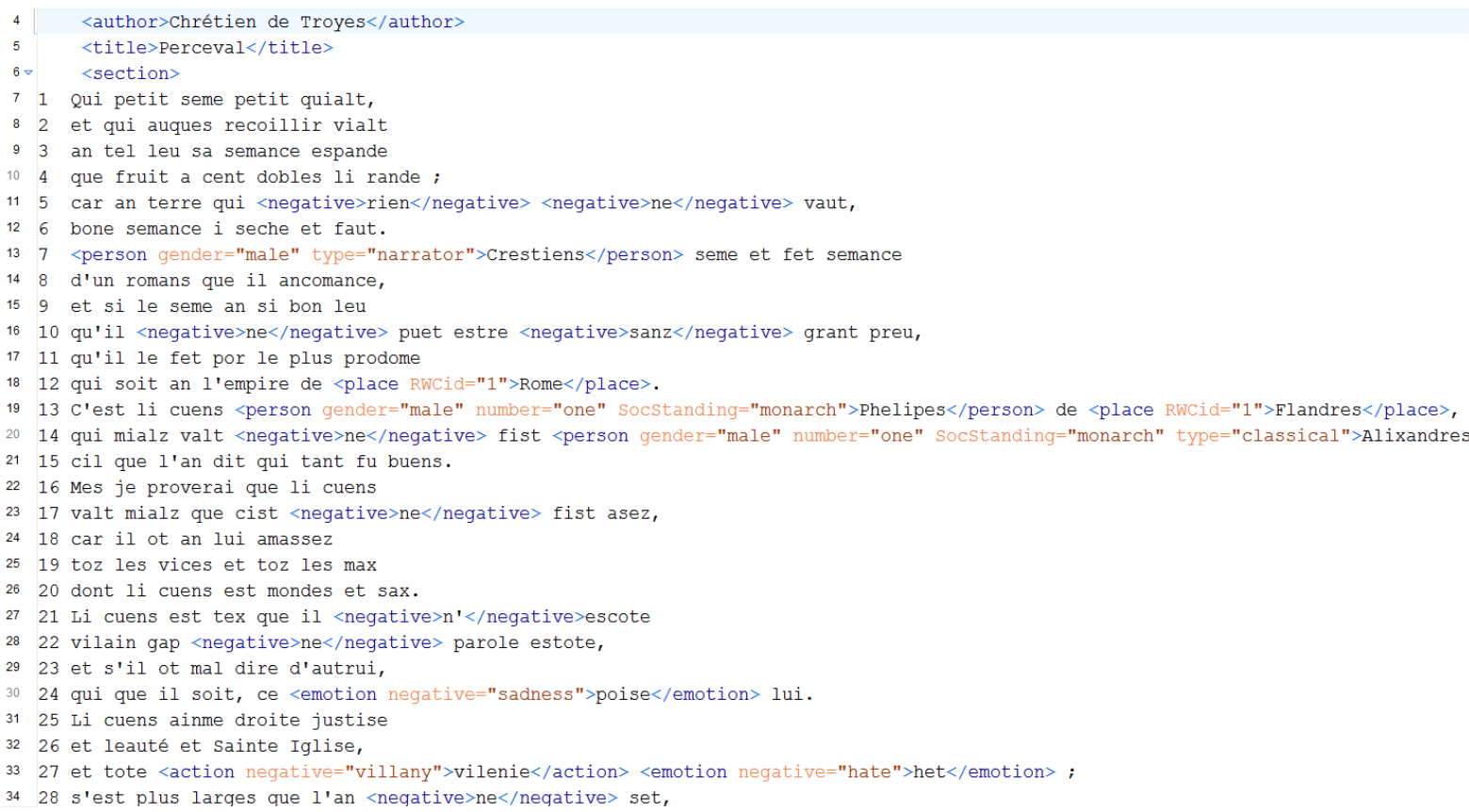

[Insert Figure 1 here: Example of the annotation of the corpus.]

The corpus was annotated manually and all elements were identified by an expert in $12^{\text {th }}$ century French and medieval romance. Although in the future, automatically identifying place and space in literary corpora of this kind might be possible, at the moment, we think that specialist knowledge is necessary due to the complexity that place in romance can present. The classification presented below, aims to help us in understanding 'place and space' in romance from the literary perspective and not a geographic, GIR, or linguistic one, although we draw upon some concepts from these to aid us. For instance, in current geo-parsing approaches, or to a non-literary-expert eye, a place-name such as 'Tintagel' might appear as a real (historical) location that is listed in gazetteers with 
coordinates. Nevertheless, Tintagel, as other place-names might be contested in the Arthurian tradition, and the expert might rather define it as a vague place instead of assigning its location to Cornwell. This is only one example of many, where insider knowledge is crucial to define correctly, among other things, whether a location is real, vague, imaginary, or a combination of these within the genre in question. Therefore, in the case of the annotation of places, the classification planned took into account, not only whether a place could be located by coordinates or not, but also the knowledge of the domain expert. As such, we devised a tailored classification according to what we termed real-world-correlation. The aim of this preliminary classification was to enable the examination of references to a wide array of locations and spaces that might be geographical or not. For this, three categories were created:

1. A first degree of real-world-correlation (RWC) was assigned to places that exist in the real world in the sense that they might be visited and found on a map at the time the romance was written. This category applies where scholars have plausibly associated place-names in romances with real world locations such as, for instance, the case of Carnant for Caerwent. This category includes place-names such as London, Nantes, Limoges, Rome, Canterbury, etc.

2. A second degree of real-world-correlation was assigned to places and spaces that seem to belong to the real world, but which cannot be linked to a definite location. This would apply to place-names such as Tintagel, Chastel du Trepas and Avalon, which are already known within the romance/ Arthurian tradition, but are not clearly identified with a precise location (at least at the time the romance is written) or which location is contested. Also in this category are puzzling place-names - which cannot be convincingly linked to any real place, but do not have an otherworldly or symbolic resonance either-as well as spaces such as woods and rivers, which seem to be located in a general area but cannot be pinned down exactly. 
3. A third degree of real-world-correlation was assigned to places which romance authors and audiences would understand as belonging to the romance world, such as Beaurepair or Dolorous Gard, with no real world reference except possibly allegorically.

Places and spaces were marked up according to this classification, and from it, we proceeded into a simple quantitative and qualitative exploratory analysis of place by type. It needs to be clarified that we did not carry out extensive analyses of these, but we merely aimed to explore in a preliminary way the advantages and disadvantages of using this approach. The idea behind this was to identify all possible uses of space and place, looking to evaluate in the first place whether this methodology facilitated the analysis and understanding of the social production of space in texts, and in this case, in medieval romances.

From this, we carried out three preliminary and simple explorations:

1. We quantified the different categories and discussed the possible meaning of the uses of different spaces and places in Chrétien's romances.

2. We produced maps from all the $1^{\text {st }}$ RWC places mentioned in the romances, as well as for each individual romance, and assessed the value of creating such maps through qualitative analysis supported by a Geographic Investment Analysis.

3. We then touched on the possibilities of exploration of the places and spaces within the $2^{\text {nd }}$ RWC category, discussing observations and new interpretations derived from these. For this, we used relative frequencies, a variation of Collocation Analysis called Geographic Collocation, and we also carried out simple statistics to analyse interesting observations about particular spaces, in this specific case, 'forests'.

We will now define how these were done:

Using regular XPath expressions in the XML document, we extracted, quantified and visualised all places and spaces in the corpus. The places classified as $1^{\text {st }}$ degree of RWC were assigned 
coordinates using Geo-Names for their mapping and visualisation. We are aware of the multiple developments on geoparsing techniques for historical corpora (Grover et al., 2010; Rupp et al., 2013; Grover and Tobin 2014; Gregory et al., 2015; Wing 2016). Nevertheless, this corpus presents many multiple challenges. For instance, place-names are in an historical language, $12^{\text {th }}$ century French, and their spelling might also vary widely. These issues are related to place reference resolution, but also to geocoding and are areas of research that we are pursuing in collaboration with GIR specialists. However, due to the difficulty on solving currently these issues and the relatively manageable size of the corpus in the meantime, it was decided to assign coordinates manually.

In addition to the quantification of different RWC categories, a Geographic Investment analysis was carried out with this dataset. This consists on a density map showing the standard deviation of the $1^{\text {st }}$ RWC places mentioned in the text. Such map highlights the focus on the geographies given to a place in the text.

In the case of the $2^{\text {nd }}$ RWC places, a variation of linguistic Collocation Analysis was also performed. This kind of analysis is formally used in Corpus Linguistics to identify the co-occurrence of linguistic forms in a text (Glynn 2014, 308). In other words, it allows us to determine which words are associated or 'collocate' with a term of our interest more than would be expected by chance alone. In this case, the terms used for the collocation analysis were specifically the places identified in the different RWC categories.

In addition, we also wanted to do a preliminary exploration of the significance of particular spaces, such as natural settings. For instance, it could be said that it has been of empirical consensus that 'forests' play an important role in romances in general, and it was therefore of great interest to observe that 'forests' were among the most mentioned places in the Chrétien's corpus. Although the frequency with which a word is used can be regarded as interesting in itself, we wanted to investigate for each of the romances if this observation is significant or more unusual than would be expected, and therefore, whether there is something further to investigate and explain. Following 
this logic, we wanted to examine from all places, whether a high number of mentions of 'forest' in each romance is due to chance, and if not, why this is so. To test this, we carried out a Log-likelihood test, setting a null hypothesis used to examine the space 'forest' in each of the romances. This hypothesis was formulated as:

Ho= Differences in the frequency of the mention of 'forests' between this romance and the corpus are a result of chance.

In addition, other 'effect-size' statistics such as the Bayes Factor and Log Ratio were also considered in this analysis testing the null hypothesis. While Log-likelihood is simply a measure of statistical significance giving how much evidence there is for the difference between two corpora, other tests such as the Bayes Factor provide a measure in degrees of evidence against the null hypothesis (Rayson, 2016). Results from the calculation of the Bayes Factor can be interpreted by the numbers given, where values between 0 and 2 are not regarded as positive evidence against the null hypothesis, 2 to 6 are regarded as positive evidence, 6 to 10 as strong evidence, and $>10$ is considered as very strong evidence against the null hypothesis (Baker 2004; Wilson 2013; Rayson $2008,2016)$. In the case of Log Ratio it also provides a measure of how important/large the difference between two corpora is for a specific keyword (Hardie 2014). All of these were calculated using the LL calculator developed by UCREL at Lancaster University ${ }^{4}$.

\section{Potential uses of this approach for humanists and new interpretations of the texts}

\subsection{The 'geographies' of Chrétien}

\footnotetext{
${ }^{4}$ http://ucrel.lancs.ac.uk/Ilwizard.html Accessed March 22, 2015.
} 
From the corpus of five romances, we identified the mention of 1640 places in total, from which 320 mentions correspond to the $1^{\text {st }}$ degree of RWC; 938 correspond to the $2^{\text {nd }}$ degree of RWC; and 39 to the $3^{\text {rd }}$ classification.

This simple quantification is already of great interest as traditional works of analysis of medieval romance have usually accused the genre of being geographically vague, where it has been argued that locations are ill-defined and do not have any correspondence with the real world (Rouse 2011, 136). This, in the first instance, seems to be an exaggeration. Our analysis shows that quite a high number of places in the romances are in fact, of first degree correlation as seen in the graphic. This, however, does not mean that medieval societies had a similar understanding of geography as we have today, and in these studies we need to contemplate the changes over time that such understandings might undergo.

In the medieval period, the spatial imagination was informed by a wide array of relationships, beliefs, conceptions of symmetry, and pilgrimage itineraries. Memory and tradition, both written and oral, played an important role, and maps in the medieval period did not render the bearer independent of local informants in the way that maps can today. Travellers unfamiliar with the route would have to stop and ask, using the maps they carried or had seen as an aide mémoire - that is, an auxiliary support to memory rather than a proscriptive ordinance-in conjunction with other sources of knowledge and narrative. The striking incorporation of romance narrative in thirteenth-century world maps like the Ebstorf and Hereford mappae mundi (Green 2008, 163-65) is illustrative of this kind of combination. Where modern cartography prizes objectivity and insists on consistency, a medieval cartographer like the Benedictine monk Matthew Paris (d.1250?) felt no compunction in amplifying the size and importance, for example, of Benedictine abbeys (Federzoni 2015, 23), sometimes making them seem much closer to a pilgrimage route than they actually were-and with good reason, too: such abbeys provided welcome lodging and provision, and a travelling Benedictine might have felt duty bound to pass by there and bring letters and news. The Early Modern 
redeployment of Euclidean (and Ptolemaic) geometry in the fields of linear perspective, optics, and cartography would later redefine conceptions of space. In contrast, medieval points of view seem itinerant, selective, imaginative, and contingent. It has often been observed that medieval knowledge of geography and distant places was much more limited than either modern ones or those of classical antiquity (Le Goff 1980, 189-90). In addition, the forms and functions of modern maps, and the conceptions of cartography they embody, derive predominantly from developments in the fifteenth century and later (Rouse 2014, 14). Perhaps only now, with the application of technology, 'layers' and filters, is it possible to read the rich and multiple stories and spaces (which can be readily imagined as strata) depicted in medieval maps and narratives, and the way they speak to each other, and to us.

As such, although the mapping of the $1^{\text {st }}$ RWC does convey to a certain degree the extent of the known medieval world (Fig. 2), it is of greater interest to observe that these places played a central role in the discourse or ideological purposes in which the text participates.

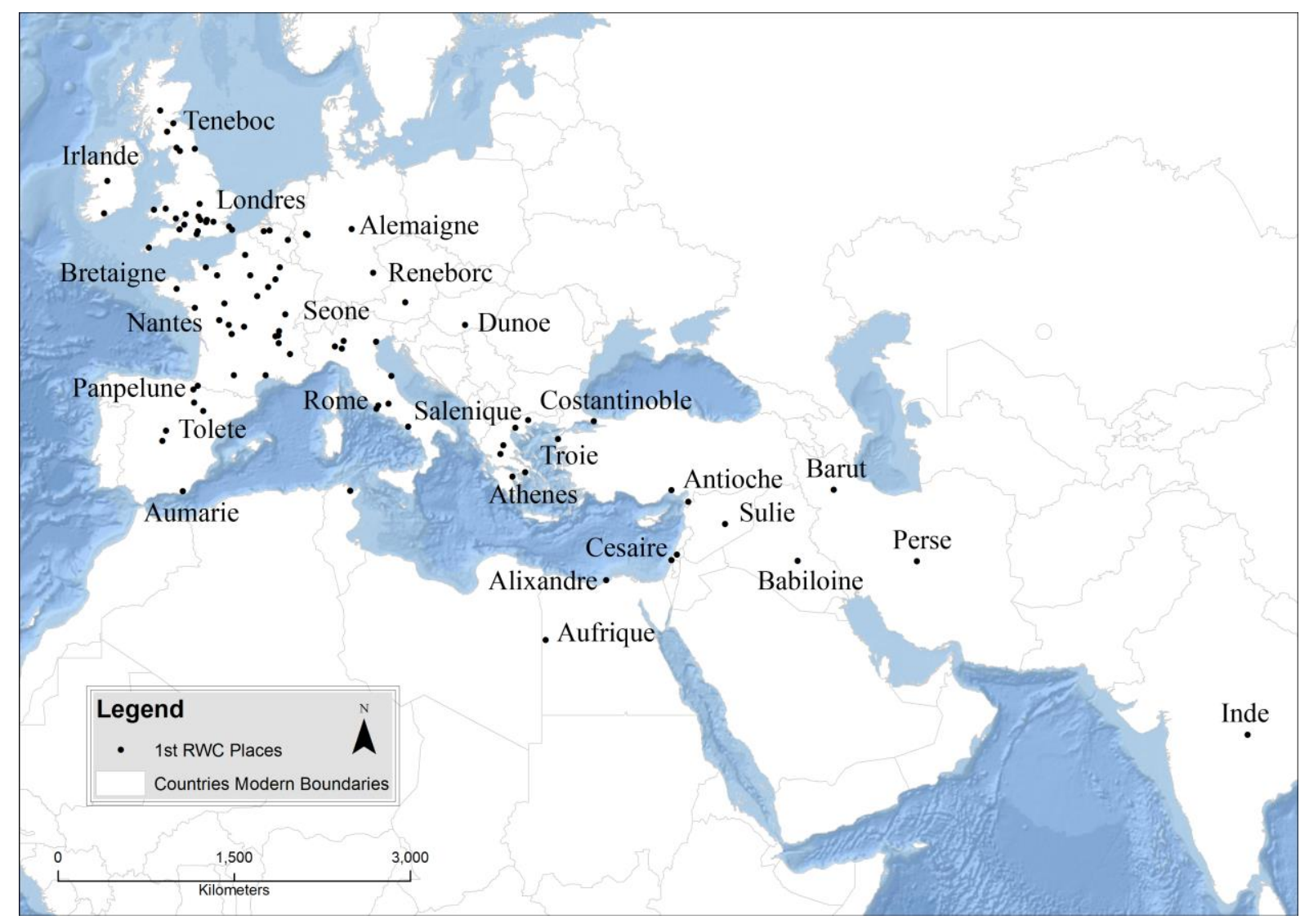


[Insert Figure 2 here: Map with $1^{\text {st }}$ RWC places showing modern boundaries and some labels of the places mentioned for reference.]

By considering the map of geographic investment (Fig. 3) which shows in terms of standard deviation the density in which these geographies are mentioned, allow us to reflect about the geographies of Chrétien's romances and the possible part they are playing. For instance, we can see that Brittany, England, and Wales, play a substantial role, rendering explicit the geographies thought of as the original locations in the stories, from which the frequencies seem to radiate outward, mimicking the paths of narrative transmission. Also prominent are the destinations of pilgrimage (Rome and Jerusalem, though not Santiago de Compostela), and the crusader possessions such as Acre and Antioch. Locations on the routes of trade and commerce-particularly the silk and spice roads-can be discerned from India through the Middle East to the Mediterranean. Also noteworthy is the visualisation we get of the translatio studii and translatio imperii, the movement of cultural hegemony, of knowledge, study, empire, and power, which Chretien traces in his prologue to Cligès, and which also follows a route described in narrative. These routes travel through time and space from Homeric Troy and Greece, to Virgilian Rome, and thence on to Western Europe. What can be observed, then, is that even in the 'real' geographies mentioned, there seems to be a sense of 'purpose', related to ideals and expectations embedded already through tradition in such places. A quick glance at the geographies mentioned in each romance reveals that they are not regarded equally or homogenously (Fig. 4). 


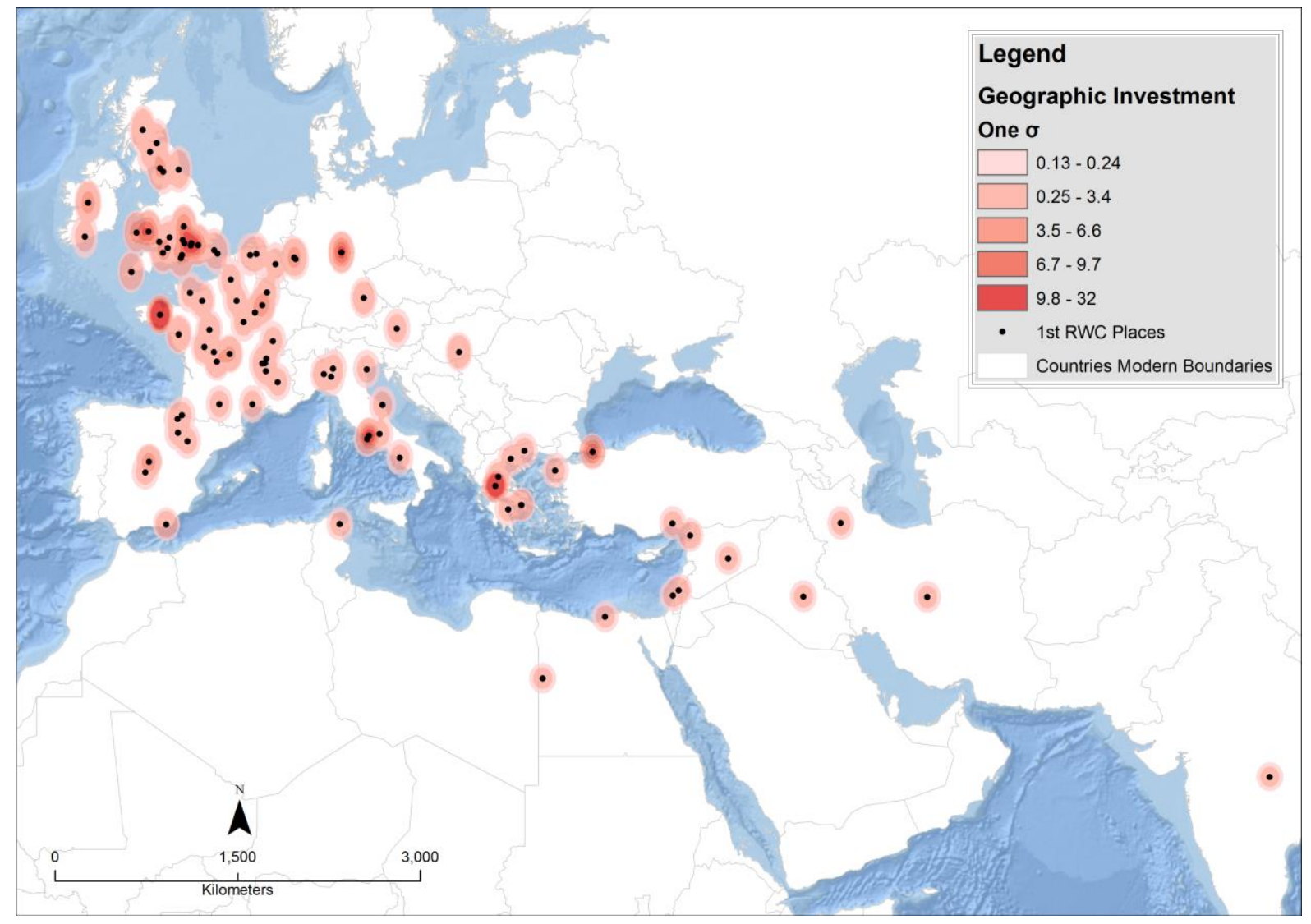

[Insert Figure 3 here: Geographic Investment in all romances. This map show in terms of standard deviation the density in which places in the romance are mentioned.]

Mapping the $1^{\text {st }} \mathrm{RWC}$ places mentioned in each romance (Fig. 4), enable us to do something that is rarely available for the study of this kind of literature. It allows us not only to have an expedite bird's-eye view of the geographies per literary work, but also to carry out a comparative assessment of these. For instance, it can be observed that Cligés is by far the most geographically oriented of Chrétien's romances. It is not only the one that contains the most extended geographies and number of references to places in the $1^{\text {st }}$ RWC classification, but it is also the one that has the lowest number of references to $2^{\text {nd }}$ degree of RWC places, and the only one that does not contain a single reference in the $3^{\text {rd }}$ degree of RWC (Fig. 5). In addition, the descriptions provided in Cligés are so detailed that it has been suggested that Chrétien might have visited England (Farina 2010, 70; Hardwood 2011, xiv). Certainly, for all its magic potions and fabulous edifices, Chrétien has situated Cligès in a world the geographies of which are more 'real', or externally recognised and referenced, 
than that of any of his other romances. The geographical orientation of this romance is first delineated in the prologue, which traces the movement of translatio studii and translatio imperii, expressed as chevalerie (knighthood, or chivalric values), from Greece to Rome to France. Cligès' highly cosmopolitan atmosphere is inflected by the particular emphasis placed on the widespread, almost global reach of influence of the Arthurian court and its chivalric ideals. As in the other romances, Arthur's court confers prestige on its adherents, but in Cligès this cultural eminence is concomitant with military force. Cligès' father, Alexander, insists on travelling from Constantinople to Britain to be knighted by Arthur himself (Duggan 2001, 316). He then travels to London to lead Arthur's army in the victorious, bloody and gruesome suppression of the rebellious Earl of Windsor. Both Alexander, the son of the emperor of Greece and Constantinople, and his son Cligés can be seen as emblematic representatives of foreign royalty and power that will fight for, ally with, and emulate Arthurian ideals. Near the end of the romance, in support of his nephew Cligès' claim to the throne, Arthur mobilises all of Europe-from England, Brittany, Normandy, Flanders and France to Acquitaine, all the way to the Pyrenees (Shichtman and Carley 1994, 61)-forming a truly international army to invade Constantinople, only desisting when Cligès is offered his rightful place as emperor. Therefore, it can be said that Arthurian power and influence is manifested by the extent and character of the geographies mentioned in and inhabited by the narrative. As Geraldine Heng has observed of Arthurian influence to and from the Levant, 'Arthurian romance furnishes the fledgling [colonies] ... with cultural authority, even as the Levantine colonies furnish Arthurian romance with narrative material in the form of ideas, plots, characters, affects, landscapes, and memory' (Heng 2003, 5-6). This makes Arthurian influence over the world unequivocal at the end of this romance. 

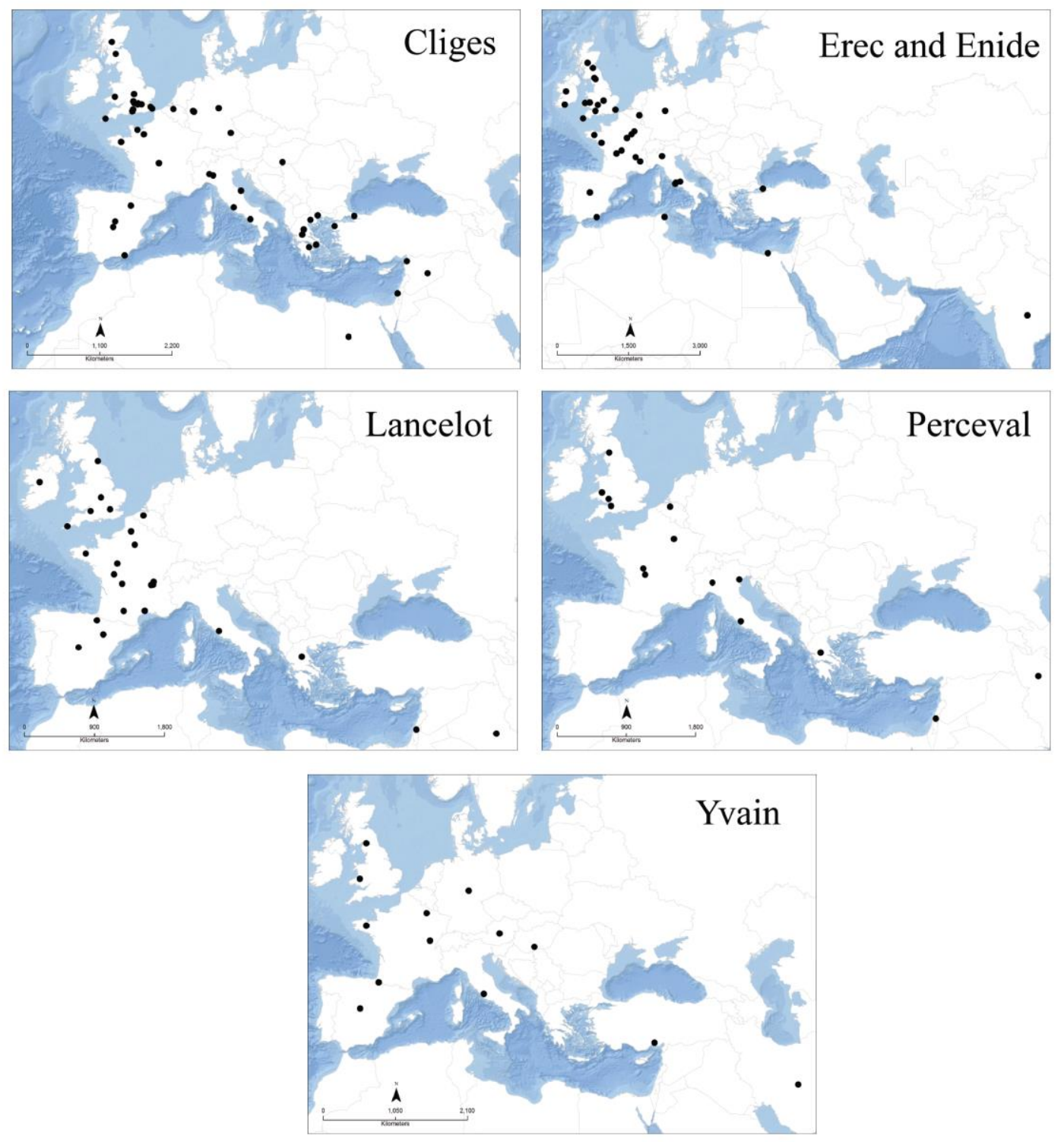

[Insert Figure 4 here: $1^{\text {st }}$ RWC places mentioned in each romance.]

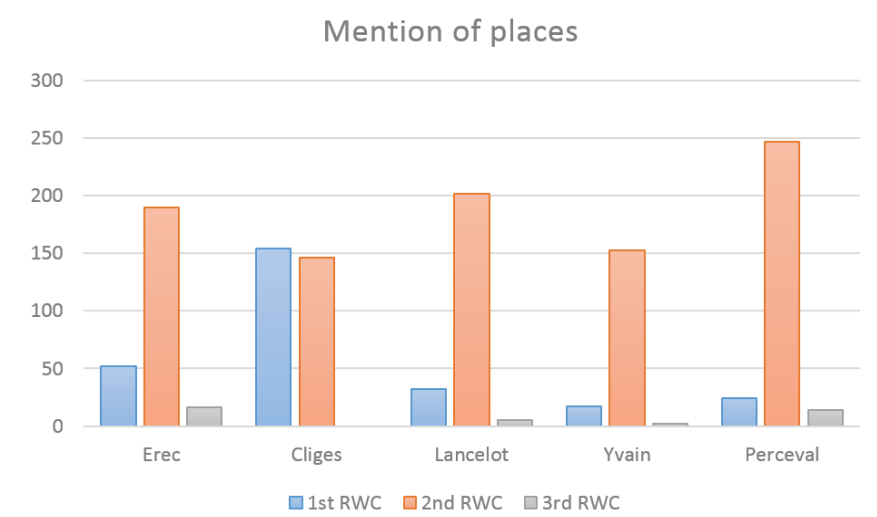

[Insert Figure 5 here: Mention of RWC places by romance] 
On this basis, it can be said that places, including geographies in the medieval context of the romance, did not simply act as settings or backgrounds, and may have been carefully selected to serve an ideological purpose or awaken meaningful associations. Nevertheless, we have to remember that these texts did not look to reproduce geographic knowledge in the sense our modern conceptions ask for (Rouse 2014, 19). This can be seen in the numerous depictions of nongeographic places recorded in them, and the approach taken here highlights this by making us notice what could be called geographies of absence or the way geographies or places that could be explicit are not made so. This is the case, for instance in Erec and Enide, when the hero refers to his father's court only as 'la terre/ Qui mon pere est et moie après./Loign est de ci, non mie pres' or 'the land which belongs to my father and will come to me afterwards. It is far from here, not at all near' (Roberts 2004, 55).

So, what are the 'other' non-geographical spaces in Chrétien's romances?

\subsection{Non-geographical place and space in romance}

Over the centuries and with the evolution of the genre, particular settings have been associated with romance and the Arthurian tradition. As said before, many of these spaces can be deemed as real but not necessarily geographical, while the status of some places as 'real' has been contested, and they might be considered to be vague. This is the case of Tintagel, Avalon, and other spaces mentioned like the sea, valleys, meadows and features such as mountains and rivers. Within the popular Arthurian imagination, forests, battlegrounds, castles and the court are among the most frequently recalled. But, what is the role that these places and spaces played in the narratives? And can we, by means of identifying, extracting, and analysing them by digital and quantitative methods facilitate the understanding of these roles and meanings? 
The importance of the court in the genre, for instance, has been pointed out multiple times in traditional scholarship, considering it as the centre of the romance world (Busby 1987, 85;

Hardwood 2011, xv). Although this can be regarded in principle as true, it is also of great interest to observe that carrying out a simple a quantification of the relative frequency of the $2^{\text {nd }}$ degree of RWC mentions in the corpus, visualised in figure 6, can help the literary scholar to quickly realise that there are many other spaces that play a significant role, and to which less attention has been given. These are, for instance, hostels, doors, forests, squares, the sea, windows, paths and towns, among others.

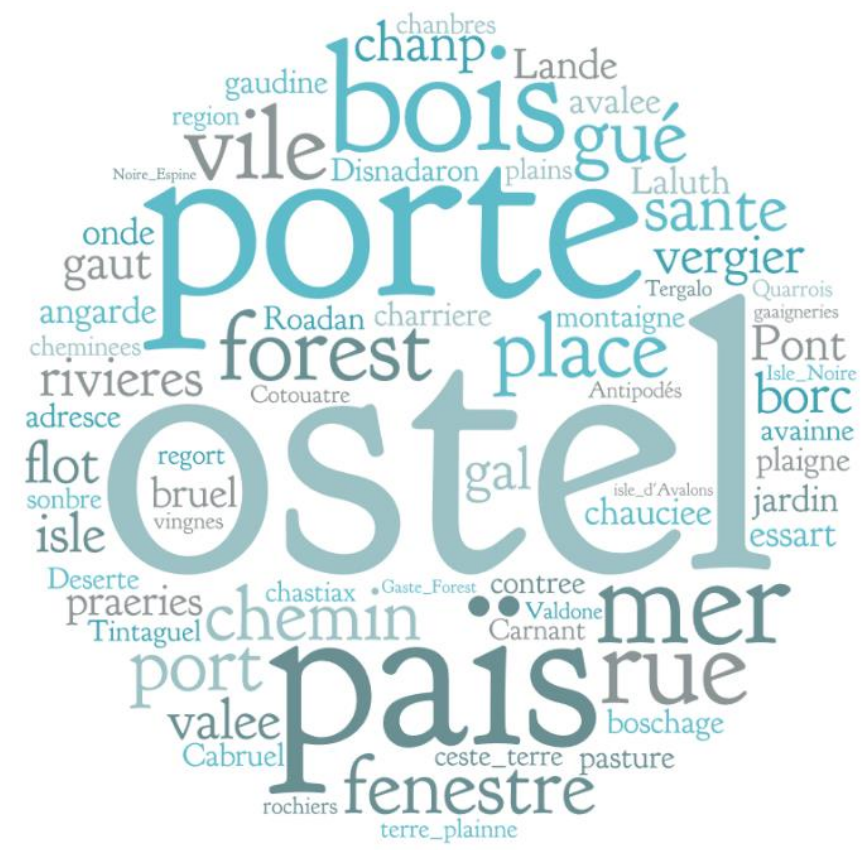

[Insert Figure 6 here: Most mentioned $2^{\text {nd }}$ RWC places.]

Hostels, for example, are the most mentioned in Erec and Enide, and they are among the three most mentioned spaces in the rest of the romances with the exception of Cligés, where they are still amid the ten most frequent. Hostel, in the context of the romance, refers to dwellings or houses where guests could be received and entertained. If we think that space can act not only as a marker of social and cultural constructions such as gender, class, and race but also as a field in which differences in social status, wealth, or power may be staged or made visible, we can start understanding why such spaces are being called into the romance. Many of the most important 
events, such as 'encountering' for the first time the damsels that will become their loves, marital 'arrangements', deals, and important conversations on quests between the heroes of the romance and characters are situated in the ostels, or lodging-places, that are often the actual houses of privileged characters.

Non-geographical spaces, therefore, take an important dimension in the romantic narrative. The analysis of space through this methodology has pointed to many other interesting observations related, for instance, to the character of actions encountered in particular spaces. Linked to this, we have detected through collocation analysis, that doors and windows tend to be heavily associated to gender, where they seem to be related to predominantly feminine endeavours. The potential to illuminate recent and ongoing explorations of medieval space and gender (Schlief 2005; Raguin 2005; Salih, 2003) is evident. In addition to these gendered thresholds, further striking and immediately observable distinctions have emerged between 'natural' environments on the one hand and built, man-made, manufactured, constructed 'interior' spaces on the other. Striking too, are the wide array of spaces that occur somewhere on a spectrum between these two counterparts: spaces such as gardens, orchards, arable, pasture, and park land, all with boundaries and frontiers, an inner and an exterior aspect. Although this will be addressed in detail in forthcoming research (MurrietaFlores and Howell 2017), it can be already suggested that such distinctions can be revealed by analysing the corpus through the presented method.

The role played by 'man-made' spaces in defining social and cultural constructions and identities has already received some attention in medieval studies (Schlief 2005; Raguin 2005). In contrast, 'natural' or exterior spaces such as paths, forests, or clearings, have been understood in two principal ways. Forests have been readily seen as liminal spaces with long histories of symbolic associations (Saunders 1993, 80-96). Other 'natural' exterior spaces have been understood as acting on a purely functional level (Brandsma 2010, 96), providing basic environmental information connected with their primary (and, it is acknowledged, important) roles as conduits for the 
adventures of the protagonists. While there might be an obvious element to the function of places in the romances to certain extent-e.g. roads are, indeed, for travelling-our analysis makes very explicit that references to these and other spaces, are more complex than simple settings. For instance, creating a lexicon of these spaces, we immediately notice that allusions to the land are very rich. There are, for instance, many ways in which 'land', this is to say a 'plot' or a piece or parcel can be referred to. "Land" in the context of the romance can take many forms, such as: sonbre (fallow-land); plaigne (plain, area of flat land); lande (heath-uncultivated land); gaaigneries (agricultural field-land under cultivation), and avainne (oat-field), among others. This wealth of terminology reflects the importance of the land, familiarity of author and audience with its different uses, and understanding of the implied distinctions of land use in terms of economy, agriculture, fertility and prosperity. More than this, the lexical richness, variety and scope of agrarian and ecological terminologies also seem to be employed in remarkable ways and in particular contexts, creating vivid imagery and narrative meaning.

This lexical and semiotic complexity can be also invested in natural features or spaces such as rivers or forests. Specific natural spaces or features often inaugurate the quest or challenges that the knights of Chrétien will have to encounter. Their importance might be indicated by their recurrence in the texts. Mentions of forests, woods and woodland-including such terms as forest, gaut, gaudine, bois, boschage, bruil-account for $14.77 \%$ of all the spaces recorded in the $2^{\text {nd }}$ degree of RWC, which can be regarded not only as high, but also as among the most frequently mentioned from all spaces and places in all the romances. Furthermore, carrying out a Log-likelihood test comparing the frequency in which 'forests' are mentioned in each romance against places in the full corpus, it was established that forests occurs more than would be expected by matter of chance alone in four out of five romances (Fig. 7). 


\begin{tabular}{|l|r|r|r|}
\hline Forest & Log-likelihood & Bayes Factor & \multicolumn{1}{|c|}{ Log Ratio } \\
\hline Erec & 11.49 & 6.57 & 0.84 \\
\hline Cliges & 41.14 & 36.37 & 2.82 \\
\hline Lancelot & 14.4 & 9.64 & 1.24 \\
\hline Yvain & 0.13 & -4.61 & 0.1 \\
\hline Perceval & 13.49 & 8.64 & 1.02 \\
\hline
\end{tabular}

[Insert Figure 7 here: Statistical tests performed at a confidence level of $p<0.01$.

This test was performed at a confidence level of $p<0.01(1 \%)$ and a critical value of 6.63 , which was surpassed in all romances, enabling us to reject the null hypothesis with the exception of Yvain. This basically means that 'forests' seem to play a very important role in the majority of romances in this corpus. These results also pointed to very stimulating observations.

Looking at the results in this particular case, it is of great interest to note that even if 'forest' is in fact the most mentioned place in Yvain, it is not only not statistically significant, but it does not present a large difference in terms of its Bayes Factor and Log Ratio when compared to the full corpus. In contrast, in the case of Lancelot and Perceval, but particularly of Cligés, the test suggests a substantial difference in the use of this term. The possible reasons behind this will be addressed in forthcoming research, but while it could be considered that specific measures such as the Bayes Factor can give us further pointers to investigate the reasons behind the observed differences, the Log-likelihood test is enough to give us an idea of the importance of the 'forest' in the texts. As has long been recognised, the forest of medieval romance often corresponds to a break from the social and socially constructed courtly environment. In the post-Freudian twentieth century, these romance spaces were implicitly understood as externalisations of the knightly protagonist's mind. The court is thus aligned with social order, and the forest with the unruly and dangerous unconscious. Thus Vermette $(1987,152)$ considered the romance forest as 'the seat of all passions'. Saunders (1993) observed that the forest could also be a space of wonder, and recalled (rightly, as did many nineteenth-century scholars) that the forest could also signify the 'wilderness' of JudeoChristian scripture. Each of these readings offers valuable insights into the forest of medieval 
romance, especially when considering exceptions, nuances and other strata of meaning suggested by specific word choice and usage in the context of the entire corpus.

The scope of Chrétien's lexical variety for forests and woodlands signals a corresponding variety of connotations which our study has begun to capture. An example of this is the emergence of a particular 'place' in the forest-a clearing, or essart-as a 'place' of uncanny and extravagant danger. A journey into the forest in romance can indeed lead the protagonist astray and lead him, as occurs at the beginning of Erec [lines 125-274] - not to the white hart being hunted - but to a mysterious, fully armed, unfriendly knight and a vicious dwarf with a knotted scourge who is his servant. And yet the forest later provides welcome cover for the protagonist who, outnumbered, successfully evades his enemies (Erec 3535, 3611). Soon after this, Erec and Enide encounter King Arthur's court, splendidly set up in idyllic surroundings in the forest. As Michael W. Twomey has recently observed in his study of Gawain and the Green Knight, 'already in Chretien de Troyes the forest is paradoxically wild and tamed' $(2013,31)$. A further complication in the forest metaphor emerges if we look more closely at the language of the dwarf episode mentioned above. The unpleasant encounter takes place in an essart, or clearing (Erec 136) in the forest. Our study has made us reflect profoundly and pay close attention to these spaces, leading us to the realisation that clearings are among the most consistently dangerous spaces in Chrétien's romances. In Yvain, wild bulls and their wicked keeper are found in one clearing (Yvain 277, 706); in another a lion thrashes in a deadly struggle with a fire-breathing serpent (Yvain, 3342). In yet another instance the word is used figuratively to describe the desolation left in the wake-not of a clearing of trees, but of people, in the slaughter of Roncesvalles (Yvain 3230). The opening description in Erec and Enide of the hunt of the White Stag organised and pursued by King Arthur, points not only to the role of the forest as a stage on which adventures will be played out, but also to its status as liminal space. The actual adventure is never concerned with the stag itself, but is rather used to introduce the hero into the forest, in which he will face multiple challenges, but also through which he will reach the sparrow-hawk tournament, leading to the adventure that will bring him Enide's hand in marriage 
(Saunders 1993). The identification of the forest as quantitatively significant in this corpus, points then to the crucial structural role that it plays in the knight's quest. In a similar fashion, many other observations have been made in the case of particular spaces in each individual romance, and we are still in the process of analysing the dataset and investigating exciting differences observed, as well as relationships that seem to exist, for instance, between public and private spaces, natural and urban settings, place and social status, and place and gender, among many others. The results from these will be published in the near future.

\section{Conclusion}

The study of spatial narratives in medieval romance is far from concluded. We are still in the process of carrying out an in-depth analysis of each of Chrétien's romances and then proceeding to a comparison between them. In addition, although this article has been concerned with the study of space and place in French medieval romance of the $12^{\text {th }}$ century, there is still a long way to go in the comparison between different traditions. It has to be remembered that these kind of explorations are new to the majority of literary scholars, and the development of these methodologies are largely experimental. As such, the main purpose of this research was to test whether approaches such as the one presented here could help and elicit new thoughts, interpretations and reflections about space and place in historical literature and particularly, medieval romances. In this sense, this research can be regarded only as an initial step into a long pathway of digital explorations of spatial narratives. It can be said that the methodology proposed here, although imperfect, has allowed not only a more integral exploration of space and place than would have been possible using a GIS approach exclusively, but also an expedited form of comparison.

It is acknowledged that there are difficulties and challenges that have to be addressed. Although in the annotation method we designed we tried to create a classification that would enable us to identify all sorts of places and spaces, we acknowledge that such classification $\left(1^{\text {st }}, 2^{\text {nd }}\right.$, and $3^{\text {rd }}$, real 
world correlation) might not be suitable for all genres and questions, and a more nuanced classification might be needed. Other challenges particularly in the case of the $1^{\text {st }}$ degree of RWC place-names, still apply, as they do everywhere from Geographic Information Retrieval to the field of Spatial Humanities, and we are currently investigating possible approaches to issues, among others, of spelling variations and identification of place-names in diverse languages (Santos et al., 2017). In addition, the annotation of the corpus is currently done manually and is reliant upon an expert, both in the language and preferably in the genre. This has obvious advantages in that the annotations are carefully done and the model can change with the experience of the scholar; disadvantages include the magnitude of the time and effort involved in annotating the corpus, and there is also still the need to look for the implementation of more universal annotation methods, either looking to integrate them for instance to systems such as Linked Data, SpaceML or TEI. Nevertheless, this also brings new challenges and questions, particularly when dealing with imaginary space and place. Nevertheless, we are taking steps towards a more expeditious and customisable solution. Taking advantage of Natural Language Processing techniques and Machine Learning we are also aiming to explore diverse methods for the semi-automated identification of locations in spatial narratives (Won et al., 2017)). In this sense, there is still the need to continue the experimentation of the intersection between different linguistic approaches and spatial technologies, with the goal of facilitating the interaction between close and distant reading. Furthermore, although the Spatial Humanities are rapidly developing, there are two main considerations that the field has to bring forward -and that we aimed to emphasise in this article- if we are to reach a better understanding of space and place in these narratives, and their changes over time: Firstly, our understanding of space and place changes with time and culture. This is nothing new, as it was Lefebvre's (1991) original proposition in 'The production of space', where he argues that historical change can be tracked though spatial understandings and forms. Secondly, based on the idea that history, literature, and spatial understanding inform and shed light on one another, all references to place and space emerge as potentially laden with significance and thus deserving of careful consideration. 
In the case of medieval romance, spaces are not blank canvases where actions can take place, but they are rather discourses of the meanings that these convey. Therefore, the battlefield and the joust are not only 'arenas', but are in fact the spaces where honour and courage are built, where love is tested and proved, and where knighthood and valour are constructed or destroyed. In the same way, more explicit references to place in later romances to Jerusalem and Bethlehem connect strongly to the Christian imagination, values, and world. In this manner, the medieval writer subtly interlaced values, ideals, and culture, reflected in the complexity of these spatial narratives. This can be sensed in how they build on the experience and imagination of the writer, but also of the audience. The development of this research connects to the exploration of how this happens, and it can be considered as an example of the multifaceted questions that humanities scholars can pose, and how the field of Digital Humanities is encountering them. Finally, it can be said that specifically in the field of Spatial Humanities, we are still in the 'infancy' of the development of computational approaches for the complex analysis of spatial narratives. However, the possibilities seem endless and as with the knights of the romances, the road that lies ahead will be full of challenges and trials, but also of adventures and victories.

\section{Acknowledgments}

The research leading to this article has received funding from the European Research Council (ERC) under the European Union's Seventh Framework Programme (FP7/2007/2013) ERC grant 'The Past in its Place' (agreement no. 284085). Thanks are due to Robert Rouse whom generously shared his research and to Bruno Martins, Philip Schwyzer, Christopher Donaldson, David Cooper, Sally Bushell and lan Gregory that have in a way or another, helped in shaping the ideas behind this research. We also thank the anonym reviewers whose constructive comments and suggestions helped us to improve the manuscript. 


\section{Bibliography}

Alves, D. and Queiroz, I. 2013. Studying urban space and literary representations using GIS: Lisbon, Portugal, 1852-2009. Social Science History. 37, (4): 457-481.

Baker, P. 2004. 'Querying Keywords Questions of Difference, Frequency, and Sense in Keywords Analysis'. Journal of English Linguistics 32 (4): 346-59. doi:10.1177/0075424204269894. Bär, Hans Rudolf, and Lorenz Hurni. 2011. 'Improved Density Estimation for the Visualisation of Literary Spaces'. The Cartographic Journal 48 (4): 309-16. doi:10.1179/1743277411Y.0000000022.

Bevan, William Latham, Henry Wright Phillott, and Francis T. (Francis Tebbs) Havergal. 1873. Mediæval Geography. An Essay in Illustration of the Hereford Mappa Mundi. London: E. Stanford. http://archive.org/details/cu31924029955428.

Busby, K. 1987. 'The Characters and the Setting'. In The Legacy of Chrétien de Troyes: Chrétien et Ses Contemporains, edited by Norris J. Lacy, Douglas Kelly and Keith Busby, 57-90. Rodopi.

Borin, L., D. Dannells, and L.J. Olsson. 2014. ‘Geographic Visualization of Place Names in Swedish Literary Texts'. Literary and Linguistic Computing 29 (3): 400-404. doi:10.1093/Ilc/fqu021.

Bushell, S. 2016. 'Mapping Fiction: Spatialising the Literary Work'. In Literary Mapping in the Digital Age, edited by David Cooper, Christopher Donaldson, and Patricia Murrieta-Flores, 125-46. Digital Research in the Arts and Humanities. New York: Routledge.

Cannadine, David. 2002. Ornamentalism: How the British Saw Their Empire. Oxford University Press. Cooper, D., and G. Priestnall. 2011. 'The Processual Intertextuality of Literary Cartographies: Critical and Digital Practices'. Cartographic Journal, November. http://www.e-space.mmu.ac.uk/espace/handle/2173/579350.

Cooper, David, Christopher Donaldson, and Patricia Murrieta-Flores, eds. 2016. Literary Mapping in the Digital Age. Digital Research in the Arts and Humanities. New York: Routledge.

Cooper, David, and lan Gregory. 2011. 'Mapping the English Lake District: A Literary GIS'. Transactions of the Institute of British Geographers 36 (1): 89-108. 
Dominguès, Catherine, and Iris Eshkol-Taravella. 2015. 'Toponym Recognition in Custom-Made Map Titles'. International Journal of Cartography 1 (1): 109-20. doi:10.1080/23729333.2015.1055935.

Donaldson, Christopher, and lan Gregory. 2016. 'Geographical Text Analysis: Digital Cartographies of Lake District Literature'. In Literary Mapping in the Digital Age, edited by David Cooper, Christopher Donaldson, and Patricia Murrieta-Flores, 67-78. Digital Research in the Arts and Humanities. New York: Routledge.

Donaldson, Christopher, lan Gregory, and Patricia Murrieta-Flores. 2015. 'Mapping "Wordsworthshire": A GIS Study of Literary Tourism in Victorian Lakeland'. Journal of Victorian Culture 20 (3): 287-307. doi:10.1080/13555502.2015.1058089.

Farina, William. 2010. Chretien de Troyes and the Dawn of Arthurian Romance. McFarland. Frisher, P. 2000. 'Sorites Paradox and Vague Geographies'. Fuzzy Sets and Systems 113 (1): 7-18. Glynn, Dylan. 2014. 'Techniques and Tools: Corpus Methods and Statistics for Semantics'. In Human Cognitive Processing, edited by Dylan Glynn and Justyna A. Robinson, 43:307-41. Amsterdam: John Benjamins Publishing Company. https://benjamins.com/catalog/hcp.43.12gly.

Gregory, Ian, and David Cooper. 2009. 'Thomas Gray, Samuel Taylor Coleridge and Geographical Information Systems: A Literary GIS of Two Lake District Tours'. International Journal of Humanities and Arts Computing 3 (1-2): 61-84. doi:10.3366/ijhac.2009.0009.

Gregory, I. N., and A. Hardie. 2011. 'Visual GISting: Bringing Together Corpus Linguistics and Geographical Information Systems'. Literary and Linguistic Computing 26 (3): 297-314. doi:10.1093/IIc/fqr022.

Gregory, Ian, Christopher Donaldson, Patricia Murrieta-Flores, and Paul Rayson. 2015. 'Geoparsing, GIS, and Textual Analysis: Current Developments in Spatial Humanities Research'. International Journal of Humanities and Arts Computing 9 (1): 1-14. doi:10.3366/ijhac.2015.0135. 
Gregory, lan, and Patricia Murrieta-Flores. 2016. 'Geographical Information Systems as a Tool for Exploring the Spatial Humanities'. In Doing Digital Humanities: Practice, Training, Research, edited by Constance Crompton, Richard J. Lane, and Raymond George Siemens, 1st edition, 177-92. New York, NY: Routledge.

Grover, C., R. Tobin, K. Byrne, M. Woollard, J. Reid, S. Dunn, and J. Ball. 2010. 'Use of the Edinburgh Geoparser for Georeferencing Digitized Historical Collections'. Philosophical Transactions of the Royal Society A: Mathematical, Physical and Engineering Sciences 368 (1925): 3875-89. doi:10.1098/rsta.2010.0149.

Grover, C., and R. Tobin. 2014. 'A Gazetteer and Georeferencing for Historical English Documents'. Proceedings of the EACL LaTeCH Workshop, no. 119-127.

Hardie, A. 2014. 'Log Ratio - an Informal Introduction | ESRC Centre for Corpus Approaches to Social Science (CASS)'. http://cass.lancs.ac.uk/?p=1133.

Harvey, David. 1990. 'Between Space and Time: Reflections on the Geographical Imagination'. Annals of the Association of American Geographers 80 (3): 418-34. doi:10.1111/j.14678306.1990.tb00305.x.

Hardwood, Cline. (Trans.) 2011. Erec and Enide by Chrétien de Troyes, University of Georgia Press. Heng, Geraldine. 2003. Empire of Magic: Medieval Romance and the Politics of Cultural Fantasy. New York: Columbia University Press.

Heuser, R., Algee-Hewitt, M., Steiner, E., and Tran, V. 2016. 'Mapping the Emotions of London, 17001900: A Crowdsourcing Experiment'. edited by David Cooper, Christopher Donaldson, and Patricia Murrieta-Flores, 25-46. Digital Research in the Arts and Humanities. New York: Routledge.

Inkpen, Diana, Ji Liu, Atefeh Farzindar, Farzaneh Kazemi, and Diman Ghazi. 2015. 'Detecting and Disambiguating Locations Mentioned in Twitter Messages'. In Computational Linguistics and Intelligent Text Processing, edited by Alexander Gelbukh, 9042:321-32. Cham: Springer International Publishing. http://link.springer.com/10.1007/978-3-319-18117-2_24 
Jeremiah, Milford A. 2000. 'The Use of Place in Writing and Literature'. Language Arts Journal of Michigan 16 (2). doi:10.9707/2168-149X.1352.

Jones, C. B., R. S. Purves, P. D. Clough, and H. Joho. 2008. 'Modelling Vague Places with Knowledge from the Web'. International Journal of Geographical Information Science 22 (10): 1045-65. doi:10.1080/13658810701850547.

Kanagavalli, V.R, and K Raja. 2013. 'A Fuzzy Logic Based Method for Efficient Retrieval of Vague and Uncertain Spatial Expressions in Text Exploiting the Granulation of the Spatial Event Queries'. In National Conference on Future Computing.

Lefebvre, Henri. 1991. The Production of Space. Oxford, OX, UK; Cambridge, Mass., USA: Blackwell. Leidner, Jochen L. 2007. 'Toponym Resolution in Text Annotation, Evaluation and Applications of Spatial Grounding of Place Names'. PhD Thesis, Unversity of Edinburgh.

Lutwack, Leonard. 1984. The Role of Place in Literature. Syracuse University Press.

Maliene, Vida, Vytautas Grigonis, Vytautas Palevičius, and Sam Griffiths. 2011. 'Geographic Information System: Old Principles with New Capabilities'. URBAN DESIGN International 16 (1): 1-6. doi:10.1057/udi.2010.25.

Mark, D., and A. Frank. 1996. 'Experiential and Formal Models of Geographic Space'. Environment and Planning B: Planning and Design 23 (1): 3-24.

Melo, Fernando, and Bruno Martins. 2016. 'Automated Geocoding of Textual Documents: A Survey of Current Approaches: Automated Geocoding of Textual Documents'. Transactions in GIS, June. doi:10.1111/tgis.12212.

McKinstry, J. 2012. 'Challenging the Authority of Identity: The Spaces of Memory in Medieval English Romance.' Doctoral, Durham University. http://etheses.dur.ac.uk/4941/.

Montello, Daniel R., Alinda Friedman, and Daniel W. Phillips. 2014. 'Vague Cognitive Regions in Geography and Geographic Information Science'. International Journal of Geographical Information Science 28 (9): 1802-20. doi:10.1080/13658816.2014.900178. 
Murrieta-Flores, P., and N. Howell. 2017. 'Charting Imaginary Places in Medieval Romance:

Comparing the spatiality of Chretién de Troyes poems.' Forthcoming

Murrieta-Flores, Patricia, Alistair Baron, lan Gregory, Andrew Hardie, and Paul Rayson. 2015.

‘Automatically Analyzing Large Texts in a GIS Environment: The Registrar General's Reports and Cholera in the 19th Century'. Transactions in GIS, n/a-n/a. doi:10.1111/tgis.12106.

Pasley, R.C, P. Clough, and M. Sanderson. 2007. 'Geo-Tagging for Imprecise Regions of Different Sizes'. In Proceedings of the 4th ACM Workshop on Geographical Information Retrieval, edited by Ross Purves. New York, NY: Association for Computing Machinery.

Piatti, B. 2016. 'Mapping Fiction: The Theories, Tools and Potentials of Literary Cartography'. In Literary Mapping in the Digital Age, edited by David Cooper, Christopher Donaldson, and Patricia Murrieta-Flores, 88-101. Digital Research in the Arts and Humanities. New York: Routledge.

Piatti, Barbara, Hans Rudolf Bär, Anne-Kathrin Reuschel, Lorenz Hurni, and William Cartwright. 2009. 'Mapping Literature: Towards a Geography of Fiction'. In Cartography and Art, 1-16. Berlin, Heidelberg: Springer Berlin Heidelberg. http://link.springer.com/10.1007/978-3-540-685692_15.

Porter, Catherine, Paul Atkinson, and lan Gregory. 2015. ‘Geographical Text Analysis: A New Approach to Understanding Nineteenth-Century Mortality'. Health \& Place 36 (November): 25-34. doi:10.1016/j.healthplace.2015.08.010.

Purves, Ross S., and Curdin Derungs. 2015. 'From Space to Place: Place-Based Explorations of Text'. International Journal of Humanities and Arts Computing 9 (1): 74-94. doi:10.3366/ijhac.2015.0139.

Rayson, P. 2016. 'Log-Likelihood and Effect Size Calculator'. Accessed July 19. http://ucrel.lancs.ac.uk/llwizard.html. 
Rayson, Paul. 2008. 'From Key Words to Key Semantic Domains'. International Journal of Corpus Linguistics 13 (4): 519-49. doi:10.1075/ijcl.13.4.06ray.

Reuschel, Anne-Kathrin, and Lorenz Hurni. 2011. 'Mapping Literature: Visualisation of Spatial Uncertainty in Fiction'. The Cartographic Journal 48 (4): 293-308. doi:10.1179/1743277411Y.0000000023.

Reuschel, Anne-Kathrin, Barbara Piatti, and Lorenz Hurni. 2013. 'Modelling Uncertain Geodata for the Literary Atlas of Europe'. In Understanding Different Geographies, edited by Karel Kriz, William Cartwright, and Michaela Kinberger, 135-57. Berlin, Heidelberg: Springer Berlin Heidelberg. http://link.springer.com/10.1007/978-3-642-29770-0_11.

Roberts, H. 2004. 'Court and Cyoeth: Crétien de Troyes' Erec et Enide and the Middle Welsh Gereint.' In Arthurian Literature XXI: Celtic Arthurian Material, edited by Ceridwen Lloyd-Morgan, 5372. DS Brewer.

Rouse, R. 2011. 'Walking (between) the Lines: Romance as Itinerary Map'. In Medieval Romance, Medieval Contexts, edited by Rhiannon Purdie, 135-47. Studies in Medieval Romance 14. Cambridge: Brewer.

---. 2014. 'What Lies Between?: Thinking Through Medieval Narrative Spatiality'. In Literary Cartographies, edited by Robert T. Tally, 13-29. New York: Palgrave Macmillan US.

\section{http://link.springer.com/10.1057/9781137449375.}

Rupp, C.J., Paul Rayson, Alistair Baron, Christopher Donaldson, lan Gregory, Andrew Hardie, and Patricia Murrieta-Flores. 2013. 'Customising Geoparsing and Georeferencing for Historical Texts'. In , 59-62. IEEE. doi:10.1109/BigData.2013.6691671.

Santos, João, Ivo Anastácio, and Bruno Martins. 2015. 'Using Machine Learning Methods for Disambiguating Place References in Textual Documents'. GeoJournal 80 (3): 375-92. doi:10.1007/s10708-014-9553-y. 
Santos, R., Murrieta-Flores, P., and Martins, B. 2017. Combining Multiple String Similarity Metrics for Effective Toponym Matching. Manuscript in preparation.

Saunders, Angharad. 2016. 'The Spatial Practices of Writing: Arnold Benner and the Possibilities of Literary GIS'. In Literary Mapping in the Digital Age, edited by David Cooper, Christopher Donaldson, and Patricia Murrieta-Flores, 147-60. Digital Research in the Arts and Humanities. New York: Routledge.

Shichtman, Martin B., and James P. Carley. 1994. Culture and the King: The Social Implications of the Arthurian Legend. SUNY Press.

Soja, Edward W. 2011. Postmodern Geographies: The Reassertion of Space in Critical Social Theory. Nachdr. Radical Thinkers. London: Verso.

Speriosu M and Baldridge J 2013 Text-driven toponym resolution using indirect supervision. In Proceedings of the Fifty-first Annual Meeting of the Association for Computational Linguistics, Sofia, Bulgaria.

Stadler, Jane, Peta Mitchell, and Stephen Carleton. 2016. Imagined Landscapes: Geovisualizing Australian Spatial Narratives. The Spatial Humanities. Bloomington: Indiana University Press. Travis, Charles. 2015. 'Visual Geo-Literary and Historical Analysis, Tweetflickrtubing, and James Joyce's Ulysses (1922)'. Annals of the Association of American Geographers, July, 1-24. doi:10.1080/00045608.2015.1054252.

Twaroch, Florian A., Christopher B. Jones, and Alia I. Abdelmoty. 2008. 'Acquisition of a Vernacular Gazetteer from Web Sources'. In , 61-64. ACM Press. doi:10.1145/1367798.1367808. Wilson, Andrew. 2013. 'Embracing Bayes Factors for Key Item Analysis in Corpus Linguistics'. In New Approaches to the Study of Linguistic Variability, edited by Markus Bieswanger and Amei Koll-Stobbe, 3-11. Frankfurt: Peter Lang. http://eprints.lancs.ac.uk/51045/. 
Wing, B.P. 2016. 'Text-Based Document Geolocation and Its Application to the Digital Humanities'. PhD Thesis, Texas: University of Texas.

Won, M., Murrieta-Flores, P., and Martins, B. 2017. Towards a Methodology for the Identification and Geocoding of Place-names in Historical Documents. Manuscript in preparation. 